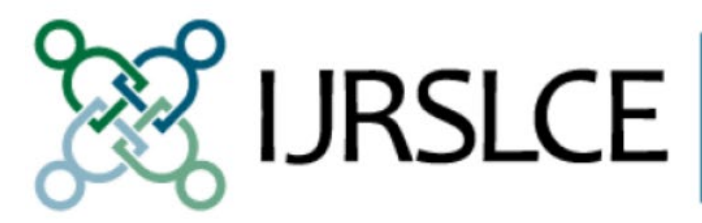

International Journal

for Research on

Service-Learning \&

Community Engagement

Volume 4 | Issue 1

Article 2

2016

\title{
Advances in Theory and Methodology
}

\section{Dan Richard}

This article was originally published at:

https://journals.sfu.ca/iarslce/index.php/journal/article/view/254/141

Recommended Citation

Richard, D. (2016). Advances in theory and methodology. International Journal of Research on Service-Learning and Community Engagement, 4(1), 1-2. 


\title{
Advances in Theory and Methodology
}

\author{
Dan Richard \\ Section Editor
}

A review of the articles selected for publication in this Advances in Theory and Methodology section of the journal highlights the vibrant conceptualization and methodological exploration that continue to characterize service-learning and community engagement research. One way to make progress in research is to replicate what has been accomplished in the past. In "Revisiting Pedagogical Variations in ServiceLearning and Student Outcomes," Dahan illustrates how he applied quasi-experimental design to test a conceptual framework proposed in a previous correlational study by Mabry (1998). By adding quasiexperimental elements and new independent and dependent variables, and by doubling the sample size of the previous study, the author confirmed Mabry's findings through a more stringent test of the hypotheses.

Other articles in this section continue the important work of distinguishing variables for refining and improving service-learning practice. In "Effect of Service-Learning on the Multicultural Competence of Teacher Candidates," Han, Hazareesingh, and Cao describe the outcomes of a study in which they compared the effects on preservice teachers of a traditional Doing For service-learning experience in an ethnically and racially diverse elementary school to a Doing With approach that included dialogue with families. Participants who received the Doing With component made greater gains than others in multicultural competence.. In "A Framework for Dialogue within Service-Learning," Taylor challenges service-learning practitioners to incorporate the 5-step community of inquiry (CI) model from the Philosophy for Children movement into classroom reflection and dialogue. The CI model lends itself to instructional applications of theoretical foundations for service-learning, including Dewey, Freire, and Butin, and to the resolution of particular issues in service-learning instruction. In "A Contextual Examination of High-Quality K-12 Service-Learning Projects," Fox and LaChenaye add welcome results to the neglected field of research on K-12 service-learning. Using grounded theory, they found that the quality of nine award-winning service-learning programs was associated with features beyond those identified in the K-12 Service Learning Standards for Quality Practice, such as human capital contributions. In a second study focused on K-12 service-learning, detailed in their article "Authentic Reflection for Experiential Learning at İnternational Schools," Perry and Martin developed a grounded theory of practices contributing to authentic reflection (i.e., reflection that is purposive and intended to influence future action). Using data from an experiential education program at international baccalaureate schools in Turkey, they found effects related to the timing of reflection, varied formats and contexts, and adviser support.

Two articles in this section highlight the challenges associated with implementing service-learning and community engagement at the institutional level. In his study described in "Measurement Matters," Kolek compared rates of student community engagement at a northeastern college using information obtained from an institutional database to engagement rates when the database was supplemented by nontraditional sources. Results indicated that traditional tracking underestimated actual student community engagement, especially among particular student groups, such as men and athletes. In "Service-Learning as an Independent Course: Merits, Challenges and the Ways Forward," Ma and Lo report on a case study of a stand-alone service-learning course at Lingnan University in Hong Kong that aimed to promote students' future civic engagement through a focus on knowledge, skills, and attitudes associated with service-learning. While the course produced the intended outcomes, it entailed challenges beyond those encountered in teaching a subject-based service-learning course. 
In 2010, Butin suggested to educators in the field of service-learning and community engagement that if we are to realize an expansion of the field, we will need to question our assumptions about the work. The authors of the articles in the current section have provided a number of challenging ideas and opportunities for meeting this goal. Taking Butin's advice, they face the future of the field with eyes open, careful reflection, and mindful steps forward.

\section{References}

Butin, D. (2010). Service-learning in theory and practice: The future of community engagement in higher education. New York: Palgrave Macmillan.

Mabry, J. B. (1998). Pedagogical variations in service-learning and student outcomes: How time, contact, and reflection matter. Michigan Journal of Community Service Learning, 5, 32-47. 